\title{
Design With Nature at 50: its enduring significance to socio-ecological practice and research in the twenty-first century
}

\author{
Frederick Steiner $^{1} \cdot$ Billy Fleming ${ }^{1}$
}

Published online: 11 September 2019

(c) Springer Nature Singapore Pte Ltd. 2019

() Laurel McSherry, Glasgow Daylight Series No. 3, stage I, January. Intaglio print, 2018

Copyeditors and computer spell checks maintain that the "w" in the "with" in the title of Design With Nature should be lower case. We capitalize it. On the original cover, all three words are capitalized, although "Design" and "Nature" are larger than "With." In his Introduction to the book Lewis Mumford observed: "McHarg's emphasis is not on either design or nature by itself, but upon the preposition with, which implies human cooperation and biological partnership." As Mumford notes, "with" emphasizes the partnership between the human activity of design and nature. $\mathrm{McHarg}$ consciously separated his approach from the Western tradition where people dominated nature. A preposition can make a difference in how we view our relationships with each other, other species, and the world around us.

Frederick Steiner

fsteiner@design.upenn.edu

Billy Fleming

wflem@design.upenn.edu

1 Ian L. McHarg Center for Urbanism and Ecology, Stuart Weitzman School of Design, University of Pennsylvania, Philadelphia, PA 19104, USA
Included in McSherry's "A Book of Days," one of three Design with Nature Now Exhibitions (http://www.arthurross gallery.org/events/event/laurel-mcsherry-a-book-of-days/).

\section{The enduring legacy of Ian McHarg}

Ian Lennox McHarg (1920-2001) drew on the environmental and social sciences of his time for his theory that we can build a better world through designing with, rather than against, nature. The Scottish-American McHarg interacted with many of the most prominent scientists and thinkers of his time to develop his ideas about an ecologically based approach to design and planning. He tested these concepts in his studios at the University of Pennsylvania (Penn) and through Philadelphia-based practice Wallace, McHarg, Roberts and Todd (WMRT). Fifty years ago, he presented the results of that practice-grounded and knowledge-based research in the landmark book Design With Nature.

Through McHarg's advocacy of ecology as a basis for design and planning, the book fundamentally changed theory in the environmental design arts. He argued that ecological knowledge should guide how we shape the built environment and how we preserve natural places. This theory spawned many practical applications from geographic information systems (GIS) and environmental assessment to new town planning and highway alignment. It also influenced diverse fields including the environmental sciences, law, geography, the social sciences, and the humanities. Through his writing, practice, and advocacy, McHarg fundamentally changed socio-ecological practice and research.

As consequential as Design With Nature was, considerable work remains for using ecology as a guide for the design and planning of the built environment. This special issue of Socio-Ecological Practice Research_- "Design With Nature at 50: Retrospect and Prospect"-re-examines the past fifty years of Design With Nature, but, equally importantly, looks ahead at how ecological knowledge can be applied in this 
first urban century to produce healthier, safer, and just communities, landscapes, and regions.

This special issue of Socio-Ecological Practice Research is timed to commemorate the 50th anniversary of Design With Nature. Whereas McHarg is generally acknowledged as the father of ecological design and planning, his contributions are frequently misunderstood and/or misrepresented. The special issue will help clarify his legacy and to extend its reach into the twenty-first century.

The purpose of the special issue is to highlight the foundational themes of McHarg's theory and practice. In doing so, the special issue seeks to:

- Analyze McHarg's position in landscape architecture, urban design, and regional planning;

- Discuss how social and ecological research and practices in fields that he pioneered have changed over the past half century;

- Review and critique aspects of McHarg's legacy; and

- Re-position the relevance and significance of $\mathrm{McHarg}$ 's contributions for landscape architecture, urban design, and regional planning.

The journal Socio-Ecological Practice Research (SEPR) is dedicated to "socio-ecological practice research, a transdisciplinary inquiry that strives to achieve the dual ambition of producing new knowledge and improving socio-ecological practice." (Xiang 2019, p. 1) This mission aligns perfectly with McHarg's ecological approach to understanding places and regions in order to guide design and planning for positive change. This special issue is nested within a broader set of activities to celebrate the 50th anniversary of Design With Nature. Several events were organized by the Penn Department of Landscape Architecture and Regional Planning (which McHarg re-established with graduate emphasis) and the Ian L. McHarg Center for Urbanism and Ecology under the title Design With Nature NOW. The events included a conference, three exhibitions, a book (Steiner et al. 2019), and other activities. (For these and other activities, please visit the Center's homepage: mcharg.upenn.edu.) Many of those efforts were necessarily focused on projects and scholars in the USA, Europe, and China-the places where McHarg's notions of designing with nature have been most fully realized. This special issue is, in part, an effort to expand the scope of our efforts to mark the 50th anniversary of his book by including a broad range of scholars.

\section{Designing the planet, with nature}

We have divided the contributions in this special issue into four categories plus a conclusion. First, four articles (Heavers; Daniels; Yang and Li; Lamb) explore the outcome of projects that McHarg documents in Design With Nature and others undertaken in the wake of its publication. Second, there is work from around the world inspired by McHarg (Evans; Mainzer and Cole; Scott et al.). Third, we include two appraisals and advances of McHarg's methods (Lieberknecht and Lim). Finally, there are critiques and discussions of his theory and ideas (Bryant and Turner; Cohen; Palazzo and Hollstein). We conclude with an essay by Socio-Ecological Practice Research editor Wei-Ning Xiang on McHarg's prescience, an illustrated chronology of McHarg's life, and a bibliography.

\subsection{Project outcomes}

WMRT undertook many design and planning projects across the nation and abroad as McHarg and his colleagues undertook applied research at Penn. McHarg's work in the 1960s with an American Institute of Architects' task force and WMRT on the Potomac River Drainage Basin was featured in Design With Nature (Potomac Planning Task Force 1967; McHarg 1969). Nathan Heavers of Virginia Tech explores the consequences of McHarg's two plansThe Potomac Report (1967) and Toward a Comprehensive Landscape Plan for Washington D.C. (Wallace, McHarg, Roberts and Todd 1967)—beyond the famous book. Heavers finds that "McHarg's ecological method has been a steady undercurrent in the planning of Washington D.C." $\mathrm{He}$ also notes that the social inequity in the District of Columbia was not adequately considered in the report or the plan, but more recent planning has.

Penn's Tom Daniels addresses The Plan for the Valleys in Baltimore County, Maryland, USA (featured in Design With Nature), and The Woodlands new town near Houston, Texas, USA (post Design With Nature). The Plan for the Valleys was a landmark study in growth management and was one of the first projects undertaken by McHarg's firm in the early 1960s. McHarg's team also undertook an ecological plan for the Texas oil man George Mitchell in the 1970s-one that aimed to integrate floodplain management, ecology, and real estate development in the Houston suburbs. Daniels observes that, although new challenges have arisen over the past 50 years, notably climate change, urban population growth, and environmental justice, McHarg's emphasis on the integration of nature and the built environment remains urgent

Bo Yang of the University of Arizona in the USA has undertaken extensive follow-up research on WMRT's plan for The Woodlands and its practical results (Yang, 2018). In their joint paper for this special issue, Yang and Shujuan Li summarize the outstanding landscape performance of The Woodlands in the face of climate change and re-assess 
McHarg's work on Interstate-95 in New Jersey (documented in Design With Nature) and project on Medford Township, New Jersey, USA (with colleague Narendra Juneja, after Design With Nature). Yang and Li illuminate McHarg's interests in social and economic factors (often overlooked by his critics) and explore the policy and practical implications of the McHarg's legacy.

Zachery Lamb, a Princeton Mellon Fellow in Urbanism and the Environment, explores McHarg-influenced plans in New Orleans, Louisiana, USA, and Dhaka, Bangladesh. He is critical for the planning emphasis on geophysical landscape processes over power, politics, and properties. Lamb contends that McHarg's work is essential for addressing contemporary urban challenges but must be updated with more attention on the politics of urbanization and environmental risk. McHarg's interest in human ecology may suggest some directions for understanding the interrelationships among people, land, other resources, power, and policy (McHarg 1981; Steiner 2016).

\subsection{Ongoing influences on practice}

Design With Nature fundamentally changed design and planning practice. Landscape architects and planners from around the world adapted McHarg's method and ecologically grounded theory.

Brian Evans of The Glasgow School of Art in Scotland, UK, has written about McHarg's influence in his native Scotland (2019). Here, Professor Evans recounts how McHarg's methods were adapted and updated in a design competition for Moscow, the Russian Federation's rapidly expanding capital city. The design team used a combination of techniques and sources from digital to landscape painting to understand, analyze, and represent the culture and ecology of the Russian landscape.

Stephen Minzer and Charles Cole of Pennsylvania State University employ McHargian suitability analysis for renewable energy infrastructure in the Appalachian Region of Pennsylvania, USA. This region has a long tradition of coal mining, which has resulted in high levels of socioeconomic distress and risk. They find that places with comparatively low levels of infrastructure density, solar potential, education, and good forest lands present both challenges and opportunities for solar energy use. The transition of coal landscape to more renewable energy producers is essential to reduce greenhouse gas production.

Dennis Scott, Dushko Bogunovich, and Matthew Bradbury from New Zealand review a 30-year effort to regenerate Waiheke Island near Auckland, New Zealand. Led by landscape architect Dennis Scott, the emphasis of this work is on designing human settlement to coexist and coevolve with local ecosystems. The results offered a radical economic and aesthetic reconsideration of the agrarian landscape in New Zealand. These authors contend that this example illustrates the global and lasting significance of Design With Nature.

\subsection{Methods of appraisal and advancement}

The methods presented in Design With Nature and McHarg's other writings continue to evolve. Katherine Lieberknecht of the University of Texas at Austin, USA, presents an assessment and update of McHarg's method for ecological surveys. She draws on WMRT's The Woodlands ecological plan and Lake Austin Growth Management Plan for inspiration. Through her work on Planet Texas 2050, Professor Lieberknecht seeks to reapply and renew McHarg's framework for socio-ecological surveys in her planning for a more resilient Texas in the face of climate and population change.

Land suitability analysis is probably McHarg's best known method. Based on a thorough ecological survey, the approach weighs opportunities to determine suitabilities for specific land uses. Theodore Lim of Virginia Polytechnic Institute and State University (Virginia Tech, for short), USA, explores impacts and opportunities two major developments in the twenty-first century presented to the use of McHarg's land suitability method. The first is the increasing evidence of non-stationary global and regional ecological conditions; the second the ever-expanding availability of high-resolution spatial data. Lim suggests ways these developments can be incorporated in land suitability analysis to enhance decisionmaking and collaboration between planners and scientists.

\subsection{Theory and criticism}

McHarg's ideas about design and planning have resulted in considerable discussion, debate, and criticisms among academics. As Margaret Bryant and Scott Turner of the State University of New York, Syracuse, USA, note, McHarg called his process "ecological planning" and his method "suitability analysis" but he never named his theory. They review his theory and then relate it to current issues in socioecological practice and research. Bryant and Turner find that McHarg's ideas about the syntropy-fitness-health nexus provide a theoretical foundation for adaptive design.

Bill Cohen of Temple University, Philadelphia, USA, identifies the theory of McHarg's and his mentor Lewis Mumford's as "ecohumanism" (see also, Cohen 2019). According to Cohen, ecohumanism rejects looking at the world only as a series of parts and embraces holism. McHarg's emphasis was on the interaction of parts through process resulting in patterns that could be read and understood. Whereas Mumford viewed ecohumanism as a synthesis of natural systems ecology with many dimensions of human systems, or human ecology, McHarg formulated and made that vision happen through his practice and research. 
Danilo Palazzo and Leah Holstein of the University of Cincinnati, USA, speculate about where McHarg derived his ideas, given that Design With Nature does not have a list of references nor are very few academic sources cited. They find the sources assorted: newspaper articles; books on ecology, biology, and planning; and television program transcripts mixed with some academic journal papers. Palazzo and Holstein probe the multiple influences on McHarg, including those from the scientists and philosophers whom he interviewed on his television program "The House We Live In" and he invited to his Penn classroom. From these varied sources, the authors note that McHarg initiated a chain reaction of impacts on academia, practice, and government.

\subsection{McHarg's prescience and life}

Wei-Ning Xiang of the University of North Carolina at Charlotte, USA, poses a provocative question: Why have McHarg's ideas proven to endure the test of time? He gives four examples where this has proven to be the case and offers four reasons why. The examples include McHarg's 1960s research and educational endeavors, the accuracy of his 1968 plan for Staten Island, the ecological plan for The Woodlands in Texas, and his 1996 initiative for global ecological restoration. Professor Xiang suggests McHarg's success was a result of: being he was a proud member of the "cryptopseudo-quasi-scientist" club; being pragmatic; having an ethical belief in human beings' enlightened self-interest; and writing in a clear, classic style.

The illustrated chronology Bill Whitaker and Fritz Steiner of University of Pennsylvania Stuart Weitzman School of Design traces McHarg's life from his birth in Clydebank outside of Glasgow, Scotland, UK, to his death in Chester County, Pennsylvania, USA. In words and pictures, the chronology highlights events in his youth, his service during the Second World War, his education in landscape architecture and city planning at Harvard, his academic career at Penn, and his practice before, during, and after WMRT. Key personal events, publications, and awards are noted as well.

The bibliography by Fritz Steiner is a comprehensive account of McHarg's books, chapters, and articles as well as professional reports, plans, and designs. Profiles, critical reviews, obituaries, interviews, films, television, videos, and other materials are included. Four books published in 2019 complete the bibliography.

\section{Prospects}

Where are we with the ideas from Design With Nature today? Both the theory and the methods have proven to be robust and adaptable. Certainly, GIS technologies have sustained and advanced methods to conduct ecological surveys, environmental assessments, and suitability analysis. The basic idea that we should design with, rather than in opposition or in control of, nature remains especially vital in the Anthropocene. On June 1, 2019, the Kentucky poet Wendell Berry tweeted "Nature is a party to all our deals and decisions, and she has more votes, a longer memory, and a sterner sense of justice than we do." ${ }^{11}$ This is a sentiment in line with McHarg's views about the intrinsic powers of nature and the necessity to design with ecological knowledge.

The advancing concept of ecosystem services also aligns with McHarg's thinking and holds the promise of furthering his methods. For instance, ecosystem services provided the foundation for the development of the SITES rating system (Steiner and Popowsky 2019). This rating system provides guidance for how to "design with nature" at the site scale. The system takes the U.S. Green Building Council's Leadership for Energy and Environmental Design (LEED) outside.

The system enables designers to rate how different environmental elements-soil, water, and plants-are employed in the planning for a park, a campus, an office complex, a waterfront, a parking lot, or a cemetery. The SITES system addresses almost anything outside beyond the building envelope. Such places can be designed to contribute to ecosystem services, conserve energy, and reduce greenhouse gas production. SITES can be employed on projects with or without buildings.

SITES is but one example of an evolving tool, grounded in McHargian theory. The social psychologist Kurt Lewin is credited with the observation that "There is nothing so practical as a good theory" (Lundberg 2004, p. 7). "Design With Nature" has certainly proven to be a practical theory. The idea is also inspirational. McHarg gave us hope that, through design and planning, we could make a difference; that we could contribute to a better world.

In the Weitzman School's Ian L. McHarg Center for Urbanism and Ecology, we're working to do just that. Our faculty have become organized around three urgent issuesbiodiversity, climate adaptation, and the Green New Deal. In each area, working groups are now engaged in research, coursework, and programming that aim to expand the scale and scope of landscape architecture in each thematic area. In our biodiversity working group, Richard Weller has become the first and only landscape architect to advise the World Bank on their conservation efforts around the globe; and Karen M'Closkey and Keith Van der Sys have begun working with the Ecuadorian Navy to map and assess the climate risks posed in the Galapagos. In our climate adaptation

\footnotetext{
${ }_{1}$ Originally part of endorsement statements for Charles E. Little's The Dying of Trees (1995).
} 
working group, Sean Burkholder and others have become an on-call research laboratory of sorts for the U.S. Army Corps of Engineers - particularly as it pertains to optimizing the Corps' dredge operations, shoreline nourishment programs, and habitat construction along the coast. In our Green New Deal working group, we're working with several members of U.S. Congress and think tanks to help with research for possible legislation, identify prototypical decarbonization and adaptation projects, and develop the public works agenda this transformative idea of Green New Deal aims to deliver-again, we've become the only landscape architects directly involved in this work. This, we hope, is how Ian might have approached the contemporary moment we now find ourselves in-diving into the data, building the case, but knowing that such work is a necessary but insufficient means of making real, lasting change; that this can only come through a commitment to activism and organizing as well.

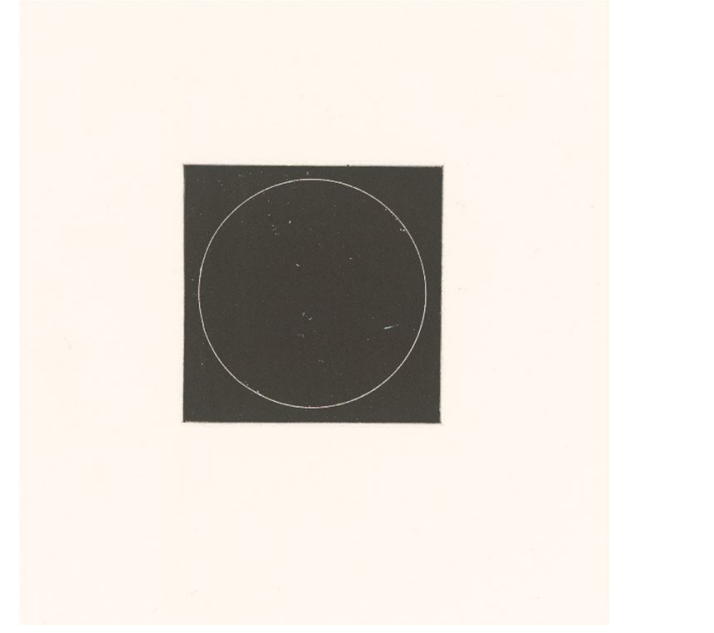

(C) Laurel McSherry, Glasgow Daylight Series, No. 4, stage I, January. Relief print, 2018

\section{References}

Cohen WJ (2019) Ecohumanism and ecological culture: the educational legacy of Lewis Mumford and Ian McHarg. Temple University Press, Philadelphia

Evans B (2019) Ian Lennox McHarg, Scotland, and the emergence of green consciousness. In: Steiner F, Weller R, M'Closkey K, Fleming B (eds) Design with nature now. Lincoln Institute of Land Policy, Cambridge

Little CE (1995) The dying of trees: the pandemic in America's forests. Penguin Books, New York
Lundberg CC (2004) Is there really nothing so practical as a good theory? Bus Horiz 47(5):7-14

McHarg IL (1969) Design with nature. Natural History Press/Doubleday, Garden City

McHarg IL (1981) Human ecological planning at Pennsylvania. Landsc Plan 8:109-120

Potomac Planning Task Force (1967) The Potomac: a report on its imperiled future and a guide for its orderly development. U.S Government Printing Office, Washington, D.C.

Steiner F (2016) Human ecology: how nature and culture changes our world. Island Press, Washington, D.C.

Steiner F, Popowsky RS (2019) The potential of the SITES for urban design. In: Banerjee T, Loukaitou-Sideris A (eds) The new urban design companion. Routledge, Abington

Steiner F, Weller R, M'Closkey K, Fleming B (eds) (2019) Design with nature now. Lincoln Institute of Land Policy, Cambridge

Wallace, McHarg, Roberts and Todd (1967) Toward a comprehensive landscape plan for Washington D.C. National Capitol Planning Commission, Washington D.C.

Xiang W-N (2019) Socio-Ecological Practice Research (SEPR): what does the journal have to offer? Socio-Ecol Pract Res 1(1):1-5. https://doi.org/10.1007/s42532-018-0001-y

Yang B (2018) Landscape performance: Ian McHarg's ecological planning in The Woodlands, Texas. Routledge, Abingdon

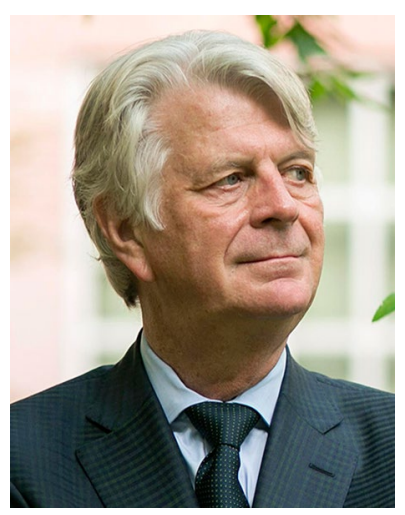

Frederick Steiner is dean and Paley Professor, and co-executive director of The Ian L. McHarg Center for Urbanism and Ecology, at the University of Pennsylvania Stuart Weitzman School of Design. He has written, edited, or co-edited 19 books, including Making Plans: How to Engage with Landscape, Design, and the Urban Environment.

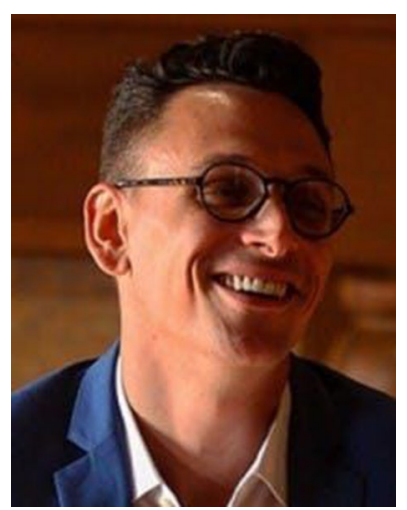

Billy Fleming is the Wilks Family Director of the Ian McHarg Center at the University of Pennsylvania Stuart Weitzman School of Design. He is co-author of The Indivisible Guide and Design With Nature Now (Lincoln 2019). Before joining Penn, Billy worked on urban policy development in the White House Domestic Policy Council during the Obama Administration. 